\title{
Ascertaining the size of the symptom iceberg in a UK-wide community-based survey
}

\author{
Anne McAteer, Alison M Elliott and Philip C Hannaford
}

\begin{abstract}
Background

The symptom iceberg describes the phenomenon that most symptoms are managed in the community without people seeking professional health care. The size of the iceberg for many symptoms is unknown, as is their association with personal characteristics, including history of a chronic disease.
\end{abstract}

Aim

To ascertain the size of the symptom iceberg in the UK.

Design of study

A UK-wide community-based postal survey.

Setting

Urban and rural communities across the UK.

Method

A postal survey was sent to an age- and sex-stratified random sample of 2474 adults, aged 18-60 years, drawn from 20 practices around the UK. Questions were aimed at investigating adults' experiences of 25 different symptoms in the previous 2 weeks.

Results

The number of symptoms experienced by one individual in the previous 2 weeks ranged from 0 to 22 (mean 3.66). Of the symptoms examined, the three most common were: feeling tired/run down; headaches; and joint pain. Univariate analysis found symptom prevalence to be significantly associated with a wide range of participant characteristics. However, after adjustment, many of these associations no longer remained significant for a number of the symptoms. Presence of a chronic condition, age, and employment status were the three factors most commonly associated with the 2-week prevalence of symptoms. Reported symptom characteristics (severity, duration, interference, and time off work) varied little by sex or age.

Conclusion

Symptoms in the UK community are common.

Symptom prevalence was associated with a number of participant characteristics, although the extent of this association was less than has been reported in previous research. This study provides an important current baseline prevalence of 25 symptoms in the community for those who do, and do not, have a chronic condition.

\section{Keywords}

community-based; epidemiology; prevalence; signs and symptoms; symptom iceberg.

\section{INTRODUCTION}

The symptom iceberg describes the phenomenon that most symptoms are managed in the community without people seeking professional health care. ${ }^{1,2}$ The visible part of the iceberg for a particular symptom represents the proportion that is presented to healthcare services; the submerged part is the proportion that is not. Research into the frequency of different symptoms (that is, the overall size of respective icebergs) and their relationship to individual characteristics, including presence of chronic conditions, informs the development of efficient symptom-based predictive models for serious disease, such as cancer referral guidelines.

A community perspective is important when researching the epidemiology of symptoms. Research based on symptoms presented to healthcare settings provides an incomplete and potentially misleading picture. So far, there have been few population-based studies of a range of different symptoms experienced in the community and most of the previous studies have been based in the US,,$^{3-5}$ Canada, ${ }^{6}$ or Scandinavia. ${ }^{7,8}$ Studies based in the UK that looked at a range of symptoms were conducted some time ago, ${ }^{9-11}$ limited to one geographical area, ${ }^{12}$ or examined symptoms associated with particular clinical conditions. ${ }^{13,14}$

A McAteer, BSc, MSc, research assistant; AM Elliott, $B S c$ (Hons), PhD, senior research fellow; PC Hannaford, MD, FRCGP, MFFP, professor of primary care, Centre of Academic Primary Care, University of Aberdeen, Aberdeen.

Address for correspondence Anne McAteer, University of Aberdeen, Centre of Academic Primary Care, Foresterhill Health Centre, Westburn Road, Aberdeen AB12 3RN. E-mail: a.mcateer@abdn.ac.uk

Submitted: 4 February 2010; Editor's response: 11 March 2010; final acceptance: 27 April 2010.

(OBritish Journal of General Practice

This is the full-length article (published online 27 Dec 2010) of an abridged version published in print. Cite this article as: Br J Gen Pract 2011; DOI: 10.3399/bjgp1 1X548910. 
Although national community-based surveys are undertaken by the UK government on a regular basis, these tend to focus on general health or a limited number of symptoms related to specific conditions. ${ }^{15-17}$ As a result, we do not have a current picture of the symptom iceberg in the UK. Such information would provide an important baseline prevalence of symptoms in the community.

This article describes patterns of symptoms in a large nationwide community-based survey of adults, including those who do, and do not, have a current chronic condition.

\section{METHOD}

\section{Subjects and sampling}

A UK-wide population-based postal survey of adults aged 18-60 years was undertaken between May 2007 and January 2008. The survey focused on those of a working age as members of older age groups are likely to have different patterns of symptoms and higher levels of comorbidity.

Following confirmation of ethical approval, an ageand sex-stratified random sample of 8000 adults was drawn from 20 general medical practices across the UK; 400 from each practice (200 men and 200 women each evenly split into four age groups: 18-30 years, 31-40 years, $41-50$ years, and $51-60$ years). GPs were asked to screen the sample and exclude anyone for whom they felt the questionnaire would be insensitive or inappropriate (for example, those with a terminal illness or severe mental impairment).

Convenience sampling was used to recruit practices from the nationally representative Medical Research Council's General Practice Research Framework. Practices varied in terms of their list size, area type (rural/urban), geographical location, and level of deprivation (Table 1). Identification and recruitment of potential participants was carried out by research nurses at each practice, with questionnaires and covering letters (signed by the local GP) sent out on the authors' behalf. A reminder letter and replacement questionnaire was sent to non-responders after 3 weeks.

\section{Questionnaire}

Twenty-five physical and psychological symptoms were included in the questionnaire. The symptoms, identified from previous literature and pilot work, ranged from those usually indicative of minor or selflimiting illness through to those that could be indicative of potentially serious conditions. Individuals were asked if they had experienced any of the symptoms during the previous 14 days. This time period was considered long enough to enable many of the symptoms to have lasted their full course, but short enough to ensure good recall of symptom

\section{How this fits in}

Symptoms are common but, to date, there have been very few populationbased studies in the UK that have examined the prevalence of a range of different symptoms, and none that have been UK wide. Such information would provide a baseline prevalence of symptoms in the community and help to inform the development of efficient symptom-based models for serious disease. This is the first UK-wide, population-based study looking at the prevalence and patterns, in the community, of 25 physical and psychological symptoms in people who do, and do not, have a chronic condition. It provides an important current baseline prevalence of symptoms in the community for comparison.

occurrence. For all symptoms experienced in the previous 2 weeks, responders indicated the severity of the symptom at its worst, how long it had lasted, how much it interfered with daily life, and how much time (if any) was taken off work as a result.

Comprehensive data on responders' characteristics were also collected to allow investigation of symptoms by a broad range of demographic and socioeconomic factors. To enable comparison between those with an existing illness and an otherwise 'healthy' population, responders were asked to indicate if they had an existing chronic condition.

\section{Analysis}

All reported $P$-values were from two-sided tests. To minimise the chances of a type 1 error from multiple testing, a conservative $P$-value of $<0.01$ was used to denote statistical significance and $99 \%$ confidence intervals (Cls) are quoted throughout.

Basic descriptive analyses were used to calculate the mean number and standard deviation (SD) of symptoms experienced in the previous 2 weeks, with independent $t$-tests and analysis of variance used to investigate associations between participant characteristics and mean number of symptoms.

Estimates of the prevalence of individual symptoms were calculated for all participants combined, and those with (that is, those who reported at least one current chronic condition) and without chronic disease separately. Binary logistic regression was used to calculate unadjusted and adjusted odds ratios (ORs) together with their 99\% Cls and $P$ values. Adjustments were made for sex, age, marital status, level of social support, level of education, housing tenure, employment status, household income, ethnicity, smoking status, and the presence of a chronic condition. Number of children was included in the univariate, but not multivariate analyses, as it was highly correlated with age and marital status.

Basic descriptive analyses were used to report the characteristics of individual symptoms. For ease of 
Table 1. GP practice data and response rates.

\begin{tabular}{|c|c|c|c|c|c|}
\hline Practice & List size & Area type $^{a}$ & $\begin{array}{l}\text { Geographical } \\
\text { location }\end{array}$ & $\begin{array}{c}\text { Carstairs } \\
\text { deprivation scores }^{b}\end{array}$ & $\begin{array}{l}\text { Corrected response } \\
\text { rate, } n(\%)\end{array}$ \\
\hline A & 15441 & Cities & Devon & 3 & $112(30.9)$ \\
\hline B & 10300 & Remote rural & Suffolk & 3 & $144(37.9)$ \\
\hline C & 12000 & Accessible small towns & Tayside & 3 & $152(40.3)$ \\
\hline $\mathrm{D}$ & 10000 & Mixed urban rural & Somerset & 2 & $155(41.0)$ \\
\hline$\underline{E}$ & 12500 & Remote rural & Somerset & 4 & $125(34.1)$ \\
\hline $\mathrm{F}$ & 12700 & Mixed urban rural & Worcestershire & 3 & $118(30.7)$ \\
\hline G & 13500 & Outer London & Kent & 3 & $124(33.9)$ \\
\hline$\underline{\mathrm{H}}$ & 10000 & Industrial & County Durham & 5 & $66(17.2)$ \\
\hline 1 & 19158 & Cities & Worcestershire & 4 & $121(32.6)$ \\
\hline $\mathrm{J}$ & 13545 & Industrial & Northamptonshire & 4 & $101(27.1)$ \\
\hline$\underline{K}$ & 7492 & Mixed urban rural & Wiltshire & 2 & $124(33.4)$ \\
\hline$\underline{\mathrm{L}}$ & 11400 & Remote rural & Pembrokeshire & 5 & $123(33.2)$ \\
\hline$M$ & 4870 & Cities & Nottinghamshire & 4 & $128(34.3)$ \\
\hline $\mathrm{N}$ & 6640 & Cities & North Yorkshire & 4 & $104(30.1)$ \\
\hline 0 & 5805 & Cities & North Yorkshire & 1 & $171(44.5)$ \\
\hline$P$ & 5850 & With new towns & Cambridgshire & 1 & $148(41.1)$ \\
\hline $\mathrm{Q}$ & 7926 & Cities & Dorset & 3 & $115(29.9)$ \\
\hline $\mathrm{R}$ & 2318 & $\begin{array}{l}\text { Other metropolitan } \\
\text { district }\end{array}$ & Greater Manchester & 2 & $103(25.8)$ \\
\hline $\mathrm{S}$ & 9210 & Mixed urban rural & Hampshire & 1 & $134(34.8)$ \\
\hline $\mathrm{T}$ & 10484 & Industrial & County Durham & 5 & $106(30.4)$ \\
\hline
\end{tabular}

${ }^{a}$ Area type classification as provided by the Medical Research Council's General Practice Research Framework. ${ }^{\circ}$ Carstairs deprivation scores ( 1 = least deprived, 5 = most deprived) are based on 2001 census data (using ward area for GP practice), available at http://cdu.census.ac.uk/related/deprivation.htm (accessed 3 May 2010).

reporting, symptom characteristics (severity, duration, interference, and time off work) were dichotomised: 'not severe' and 'severe'; 'short duration' and 'long duration'; 'low interference' and 'high interference'; 'no time off work and 'time off work'.

\section{RESULTS}

After screening, a total of 7828 questionnaires were sent out on the authors' behalf. Of these, 341 were returned as undelivered and 25 were returned as being unable to complete. Of the remaining questionnaires, 3462 (46.4\%) were returned, of which 2474 had complete data and were included in the analyses. This gave a corrected completed response rate of $33.2 \%$. Response rate varied by practice, from $17.2 \%$ to $44.5 \%$ (Table 1 ). The characteristics of sample participants are presented in Table 2, along with data from UK population surveys, to allow for comparison.

A total of 9024 symptoms in the previous 2 weeks were reported by responders. Over three-quarters reported experiencing at least one symptom, with half reporting having had between one and five symptoms. The number of symptoms experienced by any one individual ranged from 0 to 22 , with the overall mean number being $3.66(S D=3.47)$ symptoms.

Table 3 shows the mean number of symptoms experienced in the previous 2 weeks by patient characteristic among the full sample, and those with and without a chronic condition. In the full sample, there were significant associations between the mean number of symptoms and sex, age group, marital status, level of social support, number of children, level of education, housing tenure, employment status, annual household income, and smoking status. The mean number of symptoms was higher in those with a chronic condition than those without in all subgroups examined. Among those with a chronic condition, the patterns of association were very similar to the full sample, but age and number of children were no longer significant. Among those without a chronic condition there were significant associations only with sex, age, marital status, number of children, employment status, and annual household income.

Table 4 shows the reported 2-week prevalence of individual symptoms among the full sample, and those with and without a chronic condition. For the full sample, the reported prevalence varied substantially from $0.2 \%$ to $41.3 \%$. The five symptoms 
most frequently reported were: feeling tired/run down, headaches, joint pain, back pain, and difficulty sleeping. These five symptoms remained the most prevalent among those with or without a chronic condition, although the ranked order changed slightly.

The rankings were less consistent for acute symptoms (such as sore throat, cold or flu symptoms) which tended to rank higher among those without a chronic condition. The reported prevalence for all 25 symptoms was higher among those who had a chronic condition than those who did not; these differences were statistically significant for 15 symptoms.

Table 5 presents the unadjusted ORs for 2-week symptom prevalence by participant characteristics for the 20 most prevalent symptoms; the numbers of the other symptoms were too small for meaningful analysis. With the exception of ethnicity, all participant characteristics were found to be univariately associated with the prevalence of some symptoms, although this relationship varied by symptom. In general, women, those renting their home, those unable to work due to illness and others not in paid employment, ex- or current smokers, and those with a chronic condition reported having symptoms more often than those in the referent group for each characteristic. On the other hand, older age groups, those married or living together, those with medium/high social support, those with secondary or higher educational qualifications, and those with an annual household income of $\geq £ 15000$ reported having symptoms less often than the referent groups.

Although the patterns of association remained very similar, many of the factors significant at the univariate level lost their significance once adjusted for other variables (Table 6). The factors independently associated with the prevalence of each symptom varied considerably. Presence of a chronic condition, age, and employment status were the three factors most commonly associated with the 2-week prevalence of different symptoms. Sex, marital status, level of social support, household income, and smoking status were associated with fewer symptoms. Level of education, housing tenure, and ethnicity were not significantly associated with any symptoms after adjustment.

There was considerable variation in the reported characteristics of different symptoms (Table 7). Vomiting, coughing up blood, difficulty sleeping, and stomach/abdominal pain were most commonly rated as severe. Joint pain, psychological symptoms (feeling depressed, difficulty sleeping, nervousness/anxiety, and feeling tired/run down), and unintentional weight loss were the symptoms most commonly reported as being of long duration. The four psychological symptoms and vomiting had the
Table 2. Participant characteristics of symptom survey sample and UK demographics.

\begin{tabular}{lccc} 
& $n^{\mathrm{a}}$ & $\begin{array}{c}\text { Symptom survey } \\
\text { sample, } \%\end{array}$ & $\begin{array}{c}\text { UK demographics, } \\
\%\end{array}$ \\
\hline Sex & 990 & 40.2 & $49.9^{\mathrm{b}, \mathrm{c}}$ \\
Male & 1471 & 59.8 & $50.1^{\mathrm{b}, \mathrm{c}}$ \\
\hline Female & & & \\
\hline Age group, years & 203 & 8.2 & $16.5^{\mathrm{b}, \mathrm{c}}$ \\
18-24 & 393 & 16.0 & $22.2^{\mathrm{b}, \mathrm{c}}$ \\
25-34 & 631 & 25.6 & $25.8^{\mathrm{b}, \mathrm{c}}$ \\
35-44 & 686 & 27.9 & $23.0^{\mathrm{b}, \mathrm{c}}$ \\
45-54 & 548 & 22.3 & $12.5^{\mathrm{b}, \mathrm{c}}$ \\
55-60 & & & \\
\hline Marital status & 413 & 17.0 & $42.8^{\mathrm{b}, \mathrm{c}}$ \\
Single & 1798 & 73.8 & $46.2^{\mathrm{b}, \mathrm{c}}$ \\
Married/living together & 224 & 9.2 & $11.0^{\mathrm{b}, \mathrm{c}}$ \\
No longer married & & & \\
\hline Social support & 126 & 5.3 & - \\
Low & 769 & 32.4 & - \\
Medium & 1480 & 62.3 & - \\
High & & &
\end{tabular}

\begin{tabular}{llll}
\hline Number of children & & & - \\
0 & 736 & 30.2 & - \\
1 & 371 & 15.2 & - \\
2 & 869 & 35.7 & - \\
$\geq 3$ & 461 & 18.9 & - \\
\hline
\end{tabular}

\begin{tabular}{lccc}
\hline Educational status & & & - \\
No formal qualifications & 257 & 10.7 & - \\
Secondary school or equivalent & 1066 & 44.5 & - \\
Higher education & 1072 & 44.8 & - \\
\hline Housing tenure & & & \\
Owned/mortgaged & 2024 & 83.4 & $68.4^{\circ}$ \\
Council/housing association rented & 164 & 6.8 & $16.8^{\circ}$ \\
Privately rented and other & 240 & 9.9 & $14.8^{\circ}$ \\
\hline Employment status & & & \\
Full time & 1280 & 52.9 & $49.7^{\circ}$ \\
Part time & 447 & 18.5 & $15.9^{\circ}$ \\
Self-employed & 217 & 9.0 & $8.6^{\circ}$ \\
Cannot work due to illness & 102 & 4.2 & $21.4^{\circ}$ economically \\
Others not in paid work & 372 & 15.4 & inactive \\
\hline Household income, & & & \\
<15 000 & 287 & 13.0 & $\sim 20.0^{\text {c.d }}$ \\
15 000-29 999 & 566 & 25.7 & $\sim 30.0^{\text {c.d }}$ \\
30 000-49 999 & 700 & 31.8 & $\sim 40.0^{\text {c.d }}$ \\
$\geq 50$ 000 & 651 & 29.5 & $\sim 10.0^{\text {c.d }}$ \\
\hline Ethnic group & & & \\
White & 2345 & 97.4 & $92.1^{\circ}$ \\
Other & 63 & 2.6 & $7.9^{\circ}$ \\
\hline Smoking status & & & \\
Never smoked & 1334 & 55.4 & $53.0^{\circ}$ \\
Ex-smoker & 615 & 25.5 & $25.0^{\circ}$ \\
Current smoker & 461 & 19.1 & $21.0^{\circ}$ \\
\hline Chronic condition & & & \\
Yes & 1098 & 45.4 & $71.0^{\circ}$ \\
No & 1323 & 54.6 & \\
\hline
\end{tabular}

${ }^{a}$ Total numbers for each group may not add up to full sample due to missing data in participant characteristics categories. ${ }^{b}$ Working age population specifically (18-60 years). 'Office for_National Statistics data (http://www.statistics.gov.uk), accessed April 2010. ${ }^{\mathrm{A} A v e r a g e ~ g r o s s ~ i n c o m e ~ b y ~ d e c i l e ~ g r o u p s ~ o f ~ n o n-r e t i r e d ~ h o u s e h o l d s . ~}{ }^{\circ} \mathrm{General}$ Lifestyle Survey, 2008. ${ }^{16}$ tProportion of persons aged 16-64 years who reported a longstanding illness - comparable data not available. 
Table 3. Mean number of symptoms in the previous 2 weeks by participant characteristics.

\begin{tabular}{|c|c|c|c|c|c|c|}
\hline & \multicolumn{2}{|c|}{$\begin{array}{l}\text { All participants } \\
\qquad(n=2474)\end{array}$} & \multicolumn{2}{|c|}{$\begin{array}{l}\text { Chronic condition } \\
\quad\left(n=1098^{\mathrm{a}}\right)\end{array}$} & \multicolumn{2}{|c|}{$\begin{array}{l}\text { No chronic condition } \\
\qquad(n=1323)\end{array}$} \\
\hline & Mean & $P$-value ${ }^{b}$ & Mean & $P$-value ${ }^{b}$ & Mean & $P$-value ${ }^{b}$ \\
\hline \multicolumn{7}{|l|}{ Sex } \\
\hline Male & 3.31 & & 4.19 & & 2.51 & \\
\hline Female & 3.89 & $<0.001$ & 5.00 & $<0.001$ & 3.03 & 0.001 \\
\hline \multicolumn{7}{|l|}{ Age group, years } \\
\hline $18-24$ & 4.53 & & 5.40 & & 4.12 & \\
\hline $25-34$ & 3.69 & & 5.17 & & 3.02 & \\
\hline $35-44$ & 3.47 & & 4.56 & & 2.91 & \\
\hline $45-54$ & 3.58 & & 4.74 & & 2.33 & \\
\hline $55-60$ & 3.64 & 0.004 & 4.34 & 0.119 & 2.30 & $<0.001$ \\
\hline \multicolumn{7}{|l|}{ Marital status } \\
\hline Single & 4.11 & & 5.27 & & 3.44 & \\
\hline Married/living together & 3.45 & & 4.40 & & 2.65 & \\
\hline No longer married & 4.64 & $<0.001$ & 5.57 & $<0.001$ & 3.11 & $<0.001$ \\
\hline \multicolumn{7}{|l|}{ Level of social support } \\
\hline Low & 5.00 & & 6.16 & & 3.29 & \\
\hline Medium & 3.78 & & 4.91 & & 2.70 & \\
\hline High & 3.48 & $<0.001$ & 4.32 & $<0.001$ & 2.85 & 0.342 \\
\hline \multicolumn{7}{|l|}{ Number of children } \\
\hline 0 & 3.84 & & 4.95 & & 3.18 & \\
\hline 1 & 3.75 & & 4.45 & & 3.06 & \\
\hline 2 & 3.36 & & 4.38 & & 2.41 & \\
\hline$\geq 3$ & 3.93 & 0.009 & 5.03 & 0.896 & 2.78 & 0.001 \\
\hline \multicolumn{7}{|l|}{ Level of education } \\
\hline No formal qualifications & 4.71 & & 5.71 & & 2.73 & \\
\hline $\begin{array}{l}\text { Secondary school } \\
\text { or equivalent }\end{array}$ & 3.79 & & 4.82 & & 2.93 & \\
\hline Higher education & 3.28 & $<0.001$ & 4.05 & $<0.001$ & 2.75 & 0.540 \\
\hline \multicolumn{7}{|l|}{ Housing tenure } \\
\hline Owned/mortgaged & 3.43 & & 4.29 & & 2.73 & \\
\hline Privately rented and other & 4.29 & & 5.62 & & 3.35 & \\
\hline $\begin{array}{l}\text { Council/housing } \\
\text { association/rented }\end{array}$ & 5.55 & $<0.001$ & 6.81 & $<0.001$ & 3.51 & 0.011 \\
\hline \multicolumn{7}{|l|}{ Employment status } \\
\hline Full time & 3.28 & & 3.98 & & 2.74 & \\
\hline Part time & 3.49 & & 4.72 & & 2.65 & \\
\hline Self-employed & 3.08 & & 3.74 & & 2.53 & \\
\hline Cannot work due to illness & 7.29 & & 7.46 & & 5.88 & \\
\hline Others without paid work & 4.49 & $<0.001$ & 5.65 & $<0.001$ & 3.38 & 0.001 \\
\hline \multicolumn{7}{|l|}{ Household income, $£$} \\
\hline$<15000$ & 5.33 & & 6.24 & & 3.88 & \\
\hline $15000-29999$ & 3.93 & & 4.99 & & 2.95 & \\
\hline $30000-49999$ & 3.18 & & 3.93 & & 2.59 & \\
\hline$\geq 50000$ & 3.07 & $<0.001$ & 3.80 & $<0.001$ & 2.64 & $<0.001$ \\
\hline \multicolumn{7}{|l|}{ Ethnic group } \\
\hline White & 3.66 & & 4.66 & & 2.81 & \\
\hline Other & 3.92 & 0.550 & 4.80 & 0.857 & 3.34 & 0.270 \\
\hline \multicolumn{7}{|l|}{ Smoking status } \\
\hline Never smoked & 3.38 & & 4.41 & & 2.67 & \\
\hline Ex-smoker & 3.57 & & 4.23 & & 2.88 & \\
\hline Current smoker & 4.56 & $<0.001$ & 5.74 & $<0.001$ & 3.31 & 0.014 \\
\hline Overall & 3.66 & & 4.66 & & 2.83 & \\
\hline
\end{tabular}

aTotal numbers for those with and without a chronic condition does not add up to full sample due to missing data on presence of a chronic condition. ${ }^{\mathrm{b}} \mathrm{P}$-value based on t-tests (sex and ethnic group) and analysis of variance (age group, marital status, level of social support, number of children, level of education, housing tenure, employment status, annual household income, and smoking status). Bold indicates a significant difference at the $1 \%$ significance level. highest levels of interference. Fainting and gastrointestinal symptoms (including vomiting, nausea/feeling sick, and loss of appetite) were most often associated with time off work. Symptom characteristics were further explored by sex and age (data not shown); few significant associations were found.

\section{DISCUSSION}

\section{Summary of main findings}

Our population-based UK-wide survey of 25 symptoms found that over three-quarters of responders reported having had at least one symptom during the previous 2 weeks, with individuals each having an average of between three and four symptoms. The prevalence of individual symptoms varied substantially and was found to be associated with a range of participant characteristics. Presence of a chronic condition was the factor most strongly associated with symptom prevalence.

\section{Strengths and limitations of the study}

This is the first UK-wide, population-based study looking at patterns of a wide range of different symptoms in the community in people who do, and do not, have a chronic condition. The response rate was low, an increasingly common problem in epidemiological research. ${ }^{18,19}$ In addition to the usual reasons for non-response, the questionnaire was sent only to a working-age population, thereby excluding older people who are known to be more likely to respond. ${ }^{20}$ As this was a general health questionnaire not targeted at people with a specific condition, many individuals may have felt that the questionnaire was not relevant to them. ${ }^{21}$

The questionnaire was sent to a number of areas of high deprivation. Low socioeconomic status is known to be associated with poorer response rates. ${ }^{22,23}$ The primary issue with low response rate is that it introduces the potential for responder bias.

In general, men, younger age groups, those in council/housing association properties, those with household incomes $<£ 30000$ per annum, those in 'other' ethnic groups, and those who do not have a chronic condition are under-represented in the study sample, compared with the UK population. The precise impact of this on prevalence rates is difficult to assess and is likely to be mixed. For example, the relatively high proportion of those with a chronic condition in this sample may have over-estimated the prevalence of some symptoms, while the underrepresentation of those who live in council/housing association properties or those with low incomes may have under-estimated the prevalence of some symptoms.

Despite the low response rate, the relatively large 
Table 4. Reported prevalence in the previous 2 weeks for the full sample and those with and without a chronic condition.

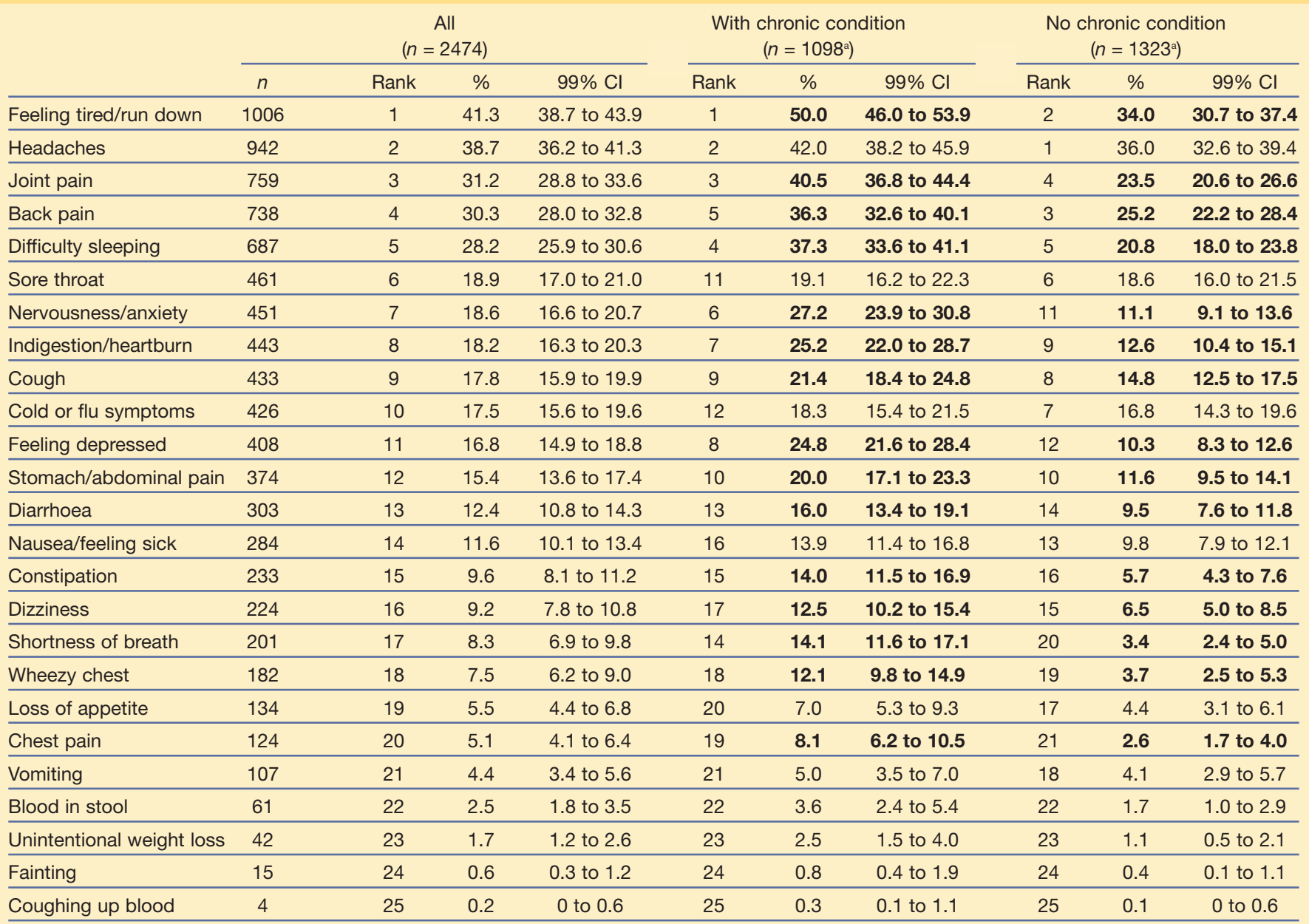

${ }^{a}$ Total numbers for those with and without a chronic condition does not add up to full sample due to missing data on presence of a chronic condition. Bold indicates a significant difference between reported prevalence of those who have a chronic condition and those who do not have a chronic condition (1\% significance level).

sample size of this study and recruitment of practices from a wide variety of geographical and socioeconomic areas has ensured that most subgroups are well represented. This allowed for important sub-group analysis and provided a good level of generalisability for the working-age population of the UK. A comparison of general health (as measured by the Short Form-36) among our responders with UK norms for a working-age population $^{24,25}$ showed very similar scores for all dimensions except bodily pain, in which this sample had poorer scores. This similarity between the general health of this study's sample and the workingage UK general population further supports the generalisability of these results.

Although the potential for residual confounding cannot be discounted, this study collected and adjusted for many more participant characteristics than has been reported in previous studies. The range of symptoms covered a broad spectrum from relatively minor to potentially serious problems, and also included a number of psychological symptoms. This has allowed us to explore patterns of symptoms in the UK in greater depth than previous studies.

The small number of responders who had some of the symptoms means that the corresponding Cls were wide, and the study probably did not have enough power to detect important differences between some groups.

\section{Comparison with existing literature}

Four other large-scale community-based studies have looked at a similar range of symptoms. ${ }^{3,4,9,12}$ Methodological differences between the studies, however, make direct comparison of prevalence rates difficult; previous studies have had different settings (time, place), participants (age groups), time frames (longer or shorter than 2 weeks), and methods of data collection (for example, interviews rather than questionnaires). In addition, symptom definitions 


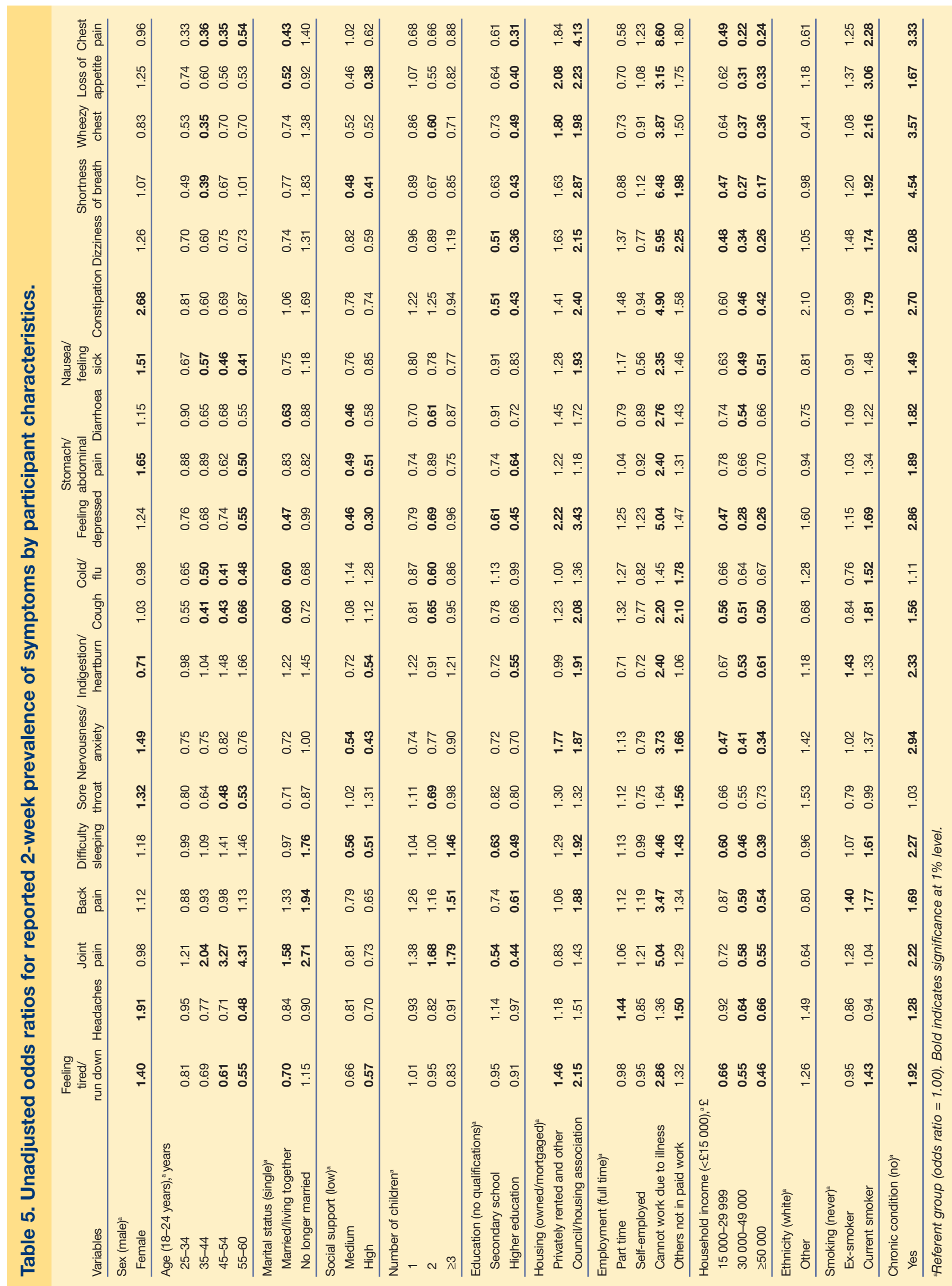




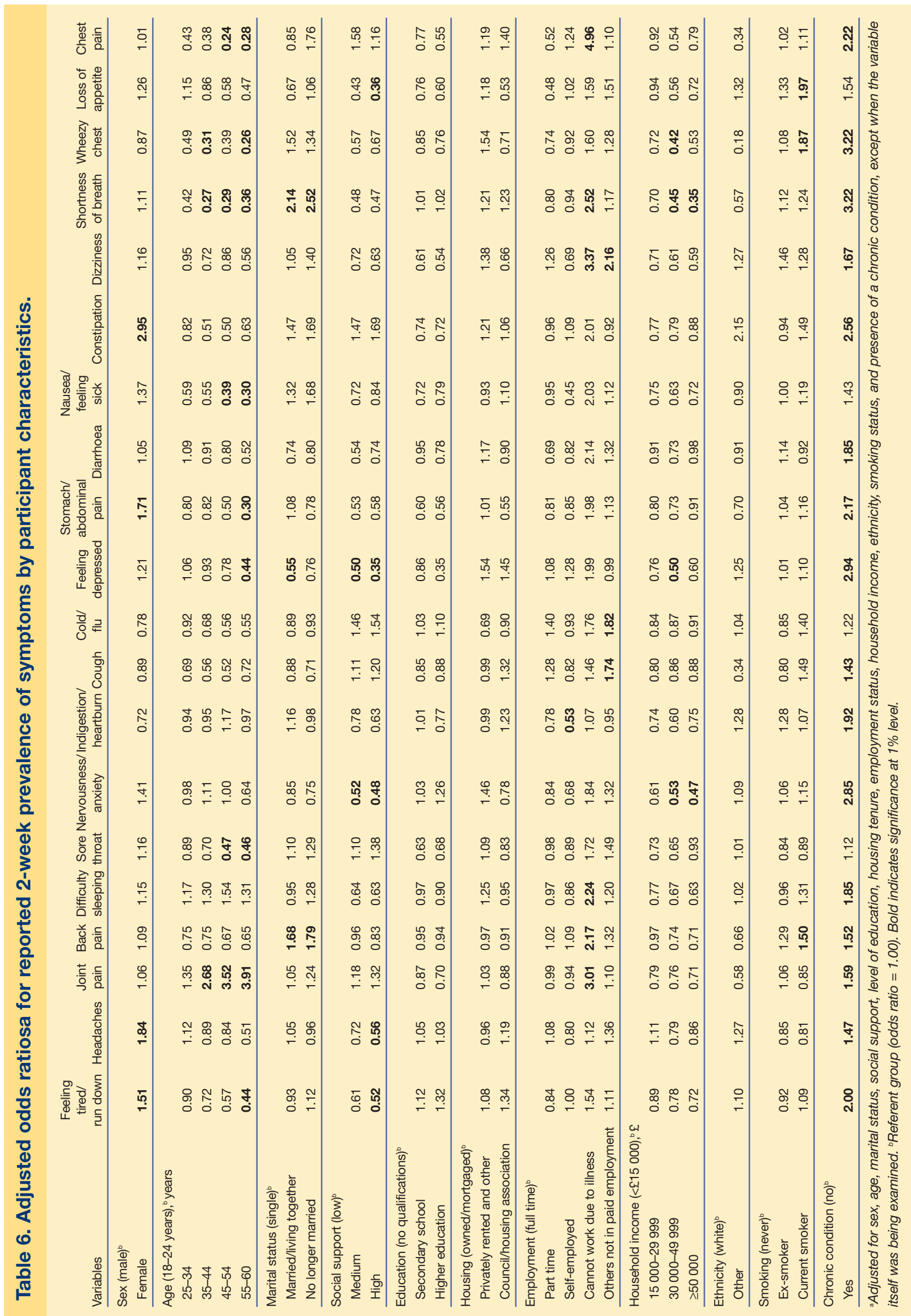




\begin{tabular}{|c|c|c|c|c|}
\hline & $\begin{array}{c}\text { Severe, }{ }^{a} \\
n(\%)\end{array}$ & $\begin{array}{c}\text { Long duration, } \\
n(\%)\end{array}$ & $\begin{array}{c}\text { High interference, } \\
n(\%)\end{array}$ & $\begin{array}{c}\text { Time off work, } \\
n(\%)\end{array}$ \\
\hline Feeling tired/run down & $143(15.3)$ & $347(35.4)$ & $217(24.1)$ & $47(7.6)$ \\
\hline Headaches & $142(15.4)$ & $30(3.3)$ & $84(9.9)$ & $34(5.8)$ \\
\hline Joint pain & $141(19.5)$ & $336(46.1)$ & $137(20.4)$ & $21(4.8)$ \\
\hline Back pain & $121(16.9)$ & $216(30.3)$ & $136(21.0)$ & $25(5.9)$ \\
\hline Difficulty sleeping & $132(20.7)$ & $270(40.7)$ & $148(23.9)$ & $25(6.2)$ \\
\hline Sore throat & $43(9.6)$ & $24(5.5)$ & $25(6.0)$ & $33(12.1)$ \\
\hline Nervousness/anxiety & $62(14.7)$ & $159(36.1)$ & $107(25.8)$ & $20(7.8)$ \\
\hline Indigestion/heartburn & $43(10.3)$ & $63(14.6)$ & $21(5.4)$ & $7(2.7)$ \\
\hline Cough & $50(12.0)$ & 69 (16.4) & $32(8.5)$ & $23(10.0)$ \\
\hline Cold or flu symptoms & $48(11.5)$ & $13(3.1)$ & $50(13.3)$ & 37 (15.2) \\
\hline Feeling depressed & $72(19.0)$ & $168(42.2)$ & $124(34.3)$ & $23(10.6)$ \\
\hline Stomach/abdominal pain & $73(20.3)$ & $59(16.7)$ & $58(16.9)$ & $31(14.4)$ \\
\hline Diarrhoea & 39 (13.5) & $28(9.6)$ & $39(14.3)$ & $18(10.6)$ \\
\hline Nausea/feeling sick & $37(13.7)$ & $25(9.0)$ & $36(13.6)$ & $37(21.4)$ \\
\hline Constipation & $23(10.4)$ & $37(16.4)$ & $16(7.8)$ & $5(4.2)$ \\
\hline Dizziness & $16(7.5)$ & $41(19.1)$ & $27(13.2)$ & $13(11.9)$ \\
\hline Shortness of breath & $25(13.1)$ & $38(19.7)$ & $31(17.6)$ & $11(11.1)$ \\
\hline Wheezy chest & $18(10.5)$ & $33(18.6)$ & $17(10.5)$ & $14(14.9)$ \\
\hline Loss of appetite & $19(15.1)$ & $17(13.4)$ & $15(12.5)$ & $5(55.6)$ \\
\hline Chest pain & $14(12.2)$ & $18(15.7)$ & $15(13.8)$ & $4(7.4)$ \\
\hline Vomiting & $26(26.5)$ & $7(6.9)$ & $26(27.1)$ & $23(37.7)$ \\
\hline Blood in stool & $4(6.9)$ & $12(20.7)$ & $5(9.6)$ & $1(4.3)$ \\
\hline Unintentional weight loss & $7(19.4)$ & $13(37.1)$ & $5(14.3)$ & 0 \\
\hline Fainting & $2(14.3)$ & $1(7.1)$ & $2(14.3)$ & $4(44.4)$ \\
\hline Coughing up blood & $1(25.0)$ & $2(50.0)$ & 0 & 0 \\
\hline
\end{tabular}

varied (for example, Kroenke and Price ${ }^{3}$ used the term 'insomnia' rather than 'difficulty sleeping'). All these factors will affect reported findings; as an example, the generally lower prevalence rates in Hannay's study ${ }^{9}$ are likely to be due, in part, to the fact that it was an interview rather than a questionnaire study and that participants included children as well as adults.

Despite the difficulties in conducting a direct comparison, in general, the current findings seem to be broadly consistent with previous symptom research in that feeling tired, headache, musculoskeletal symptoms (joint pain, back pain), respiratory symptoms (cold/flu, cough, wheezy chest), and difficulty sleeping have consistently been found to be among the most commonly reported symptoms. ${ }^{4,5,8,10}$ Studies wishing to investigate whether the prevalence of specific symptoms has changed over time would need to use the same study design and data collection methods applied to the same population.
Sex differences in the reporting of symptoms have commonly been reported in previous research. As with previous studies, ${ }^{3,8,26,27}$ this study found that women reported a higher prevalence of most symptoms than men. However, when other differences between participants were taken into account, sex differences were significant in only four of the symptoms examined. This suggests that sex may be less of a factor in the reporting of symptoms than previously believed. A similar finding was reported in a recent study by Jackson et $a l,{ }^{28}$ who found no differences in the type, duration, or severity of physical symptoms between men and women attending a walk-in clinic.

Contrary to findings from previous studies, ${ }^{3,8}$ this study found that participants in the youngest age group were significantly more likely to report having many of the symptoms examined than those in the older age groups. There are a number of possible explanations for this. This study only investigated people aged $<60$ years; older adults may experience 
more symptoms. In addition, this study had fewer responders in the youngest age group; it is possible that the younger people who responded were less well than similarly aged non-responders, resulting in a higher reported prevalence in this group. Finally, several of the symptoms that the younger age groups were more likely to report having were minor ones that older people might normalise, and so be less likely to report.

Low socioeconomic status has always been strongly linked with ill health ${ }^{29}$ and, as such, it was not unexpected that participants with lower household income, lower levels of education, and those living in council or housing association properties reported more symptoms. Importantly, after adjusting for other participant characteristics, only household income was associated with symptom prevalence, and then for only four of the symptoms examined.

Unsurprisingly, the presence of a chronic condition had a considerable influence on symptom prevalence. Previous studies have not tended to take presence of chronic condition into account when reporting symptom prevalence; this means that they are likely to have over-estimated symptom prevalence in the 'healthy' population. Therefore, this study provides an important baseline prevalence of 25 symptoms in the community for future comparisons.

Reported symptom characteristics give an important indication of symptom impact and are likely to affect how people manage their symptoms. In general, the proportion of symptoms that people rated as being severe, of long duration, high interference, or resulting in time off work was relatively small. Neither sex nor age was consistently or strongly associated with reported symptom characteristics.

\section{Implications for future research}

This UK-wide study provides an important picture of patterns of symptoms in those who have, and do not have, existing chronic conditions, as well as giving a useful current baseline prevalence of symptoms in the community for future comparison. Many symptoms were found to be common and were associated with a number of participant characteristics, although the extent of this association was less than has been reported in previous research. Information on the patterns of symptoms informs the development of predictive models for serious disease, such as cancer referral guidelines. The fact that many of the symptoms examined in this study were found to be common, and are unlikely to be linked to serious disease, highlights the need to remember that the positive predictive value of many individual symptoms is likely to be low.

In addition to having an important impact for individuals, symptoms also have important implications for the organisation of healthcare services. Future research needs to examine how people respond to their symptoms in order to optimise healthcare services.

\section{Funding}

Alison Elliott received a Career Research Development Fellowship from The Wellcome Trust. There was no direct involvement by the funder in any aspects of the study.

\section{Ethical approval}

MREC approval for the study was granted by the Fife and Forth Valley Research Ethics Committee (Ref. 06/S0501/71).

\section{Competing interests}

The authors have stated that there are none.

\section{Acknowledgements}

We would like to thank the GPs, research nurses, and administrative staff at the 20 GP practices that participated in this research, as well as our colleagues in the Medical Research Council's General Practice Research Framework, who assisted in recruiting the practices. We would also like to thank Professors Sally Wyke and Mandy Ryan, and Mrs Kate Hunt, steering committee members, for their contribution to the development of the symptoms questionnaire.

\section{Discuss this article}

Contribute and read comments about this article on the Discussion Forum: http://www.rcgp.org.uk/bjgp-discuss

\section{REFERENCES}

1. Last JM. The iceberg "Completing The Clinical Picture" in general practice. Lancet 1963; 7297: 28-31.

2. Hannay DR. The 'iceberg' of illness and 'trivial' consultations. $J R$ Coll Gen Pract 1980; 30: 551-554.

3. Kroenke K, Price RK. Symptoms in the community. Prevalence, classification, and psychiatric comorbidity. Arch Intern Med 1993; 153: $2474-2480$.

4. Hammond EC. Some preliminary findings on physical complaint from a prospective study of 1,064 men and women. Am J Public Health Nations Health 1964; 54(1): 11-23.

5. Verbrugge LM, Ascione FJ. Exploring the iceberg. Common symptoms and how people care for them. Med Care 1987; 25: 539-569.

6. Freer C. Self-care: a health diary study. Med Care 1980; 18: 853-861.

7. Molarius A, Janson S. Self-rated health, chronic diseases, and symptoms among middle-aged and elderly men and women. J Clin Epidemiol 2002; 55: 364-370.

8. Krantz G, Ostergren PO. Common symptoms in middle aged women: their relation to employment status, psychosocial work conditions and social support in a Swedish setting. J Epidemiol Community Health 2000; 54: 192-199.

9. Hannay DR. Symptom prevalence in the community. J R Coll Gen Pract 1978; 28: 492-499.

10. Banks MH, Beresford SA, Morrell DC, et al. Factors influencing demand for primary medical care in women aged 20-44 years: preliminary report. Int J Epidemiol 1975; 4: 189-195.

11. Morrell DC, Wale CJ. Symptoms perceived and recorded by patients. J R Coll Gen Pract 1976; 26: 398-403.

12. Wyke S, Hunt K, Ford G. Gender differences in consulting a general practitioner for common symptoms of minor illness. Soc Sci Med 1998; 46: 901-906.

13. Iversen L, Hannaford PC, Price DB, Godden DJ. Is living in a rural area good for your respiratory health? Results from a crosssectional study in Scotland. Chest 2005; 128: 2059-2067.

14. Hamilton W, Peters TJ, Round A, Sharp D. What are the clinical features of lung cancer before the diagnosis is made? A population based case-control study. Thorax 2005; 60: 1059-1065.

15. The Health and Social Care Information Centre. Health Survey for England. http://www.ic.nhs.uk/statistics-and-datacollections/health-and-lifestyles-related-surveys/health-survey-forengland (accessed 19 Nov 2010). 
16. UK National Statistics. General Lifestyle Survey 2008 www.statistics.gov.uk/downloads/theme_compendia/GLF08/Genera LifestyleSurvey2008.pdf (accessed 19 Nov 2010).

17. The Scottish Government. Scottish Health Survey. www.scotland.gov.uk/Topics/Statistics/Browse/Health/scottishhealth-survey (accessed 19 Nov 2010).

18. Galea S, Tracy M. Participation rates in epidemiologic studies. Ann Epidemiol 2007; 17: 643-653.

19. Morton LM, Cahill J, Hartge P. Reporting participation in epidemiologic studies: a survey of practice. Am J Epidemiol 2006; 163: 197-203.

20. Dunn KM, Jordan K, Lacey RJ, et al. Patterns of consent in epidemiologic research: evidence from over 25,000 responders. Am J Epidemiol 2004; 159: 1087-1094.

21. Edwards P, Roberts I, Clarke M, et al. Increasing response rates to postal questionnaires: systematic review. BMJ 2002; 324: 1183

22. Korkeila K, Suominen S, Ahvenainen J, et al. Non-response and related factors in a nation-wide health survey. Eur J Epidemiol 2001;
17: 991-999.

23. Van Loon AJ, Tijhuis M, Picavet HS, et al. Survey non-response in the Netherlands: effects on prevalence estimates and associations. Ann Epidemiol 2003; 13: 105-110.

24. Brazier JE, Harper R, Jones NM, et al. Validating the SF-36 health survey questionnaire: new outcome measure for primary care. $B M$ 1992; 305: 160-164.

25. Jenkinson C, Coulter A, Wright L. Short form 36 (SF36) health survey questionnaire: normative data for adults of working age. BMJ 1993; 306: 1437-1440.

26. Mechanic D. Sex, illness, illness behavior, and the use of health services. Soc Sci Med 1978; 12: 207-214.

27. Verbrugge LM. Gender and health: an update on hypotheses and evidence. J Health Soc Behav 1985; 26: 156-182.

28. Jackson JL, Chamberlin J, Kroenke K. Gender and symptoms in primary care practices. Psychosomatics 2003; 44: 359-366.

29. Marmot MG, Kogevinas M, Elston MA. Social/economic status and disease. Annu Rev Public Health 1987; 8: 111-135. 